Article

\title{
Free Base Porphyrins as Ionophores for Heavy Metal Sensors
}

\author{
Dana Vlascici $^{1, *}$, Eugenia Fagadar Cosma ${ }^{2}$, Elena Maria Pica ${ }^{3}$, Viorica Cosma ${ }^{3}$, \\ Otilia Bizerea ${ }^{1}$, Gheorghe Mihailescu ${ }^{4}$ and Liliana Olenic ${ }^{4}$ \\ 1 West University of Timisoara, 4 V. Parvan Ave, Timisoara 300223 Timis, Romania \\ 2 Institute of Chemistry -Timişoara of Romanian Academy, 24 M. Viteazul Ave, 300223-Timisoara, \\ Romania \\ 3 Technical University of Cluj-Napoca, Faculty of Science and Materials Engineering, 15 Constantin \\ Daicoviciu Street, 400020 Cluj-Napoca, Romania \\ 4 Nationale Institute of Research and Development for Isotopic and Molecular Technologies, 71-103 \\ Donath Street 400293, Cluj-Napoca, Romania \\ E-Mails: efagadar@yahoo.com (E.F.C.); epica@yahoo.com (E.M.P.); vioricacosma@yahoo.com \\ (V.C.); obizerea@yahoo.com (O.B.); gigim@itim-cj.ro (G.M.); olenic@itim-cj.ro (L.O.) \\ * Author to whom correspondence should be addressed; E-Mail: danavlascici@yahoo.com; Tel.: +40- \\ 256-592633; Fax: +40-256-592620
}

Received: 25 July 2008; in revised form: 13 Aug 2008 / Accepted: 21 Aug 2008 / Published: 25 August 2008

\begin{abstract}
Two functionalized porphyrins: 5,10,15,20-tetrakis(3,4-dimethoxyphenyl) porphyrin (A) and 5,10,15,20-tetrakis(3-hydroxyphenyl)porphyrin (B) obtained and characterized by us were used as ionophores (I) for preparing PVC-based membrane sensors selective to $\mathrm{Ag}^{+}, \mathrm{Pb}^{2+}$ and $\mathrm{Cu}^{2+}$. The membranes were prepared using three different plasticizers: (bis(2-ethylhexyl)sebacate (DOS), dioctylphtalate (DOP), o-nitrophenyl octyl ether (NPOE) and potassium tetrakis(4-chlorophenyl)borate (KTCIPB) as additive. The functional parameters (linear concentration range, slope and selectivity) of the sensors with membrane composition: (I:PVC:KTClPB:Plasticizer) in different ratios were investigated. The best results were obtained for the membranes in the ratio I:PVC:KTCIPB:Plasticizer 10:165:5:330. The influence of $\mathrm{pH}$ on the sensors response was studied. The sensors were used for a period of four months and their utility has been tested on synthetic and real samples.
\end{abstract}

Keywords: Porphyrins, ionophores, sensors, heavy metals, PVC-matrix. 


\section{Introduction}

Potentiometric determination of ions offers advantages such as high selectivity, sensitivity, good precision, simplicity, portable, non-destructive analysis and low cost. Many porphyrins [1-10] and metalloporphyrins were used in the last years as ionophores because of the importance of developing new polymeric membrane ion-selective electrodes.

A silver-selective electrode based on meso-tetratolylporphyrin was reported [1]. The electrode showed a Nernstian answer with a slope of $59.2 \mathrm{mV} /$ decade in a working concentration range of $10^{-7}-$ $10^{-1} \mathrm{M} \mathrm{Ag}^{+}$. The response time of the electrode was less than $10 \mathrm{~s}$ with a lifetime of 3 months. The electrode was used for the determination of silver in real samples and as an indicator electrode in potentiometric titrations. Determination of silver ion by simple methods is very important in chemical, clinical and environmental analysis due to the increasing use of silver compounds in industry and medicine.

Lead-selective electrodes have been extensively reported because of the toxic effects of lead on human health on one hand, and its increased industrial on the other. Among them, one lead-selective sensor based on porphyrins was reported. The sensor is based on meso-tetraphenylporphyrin as ionophore and has a working concentration range between $10^{-5}-10^{-2} \mathrm{M} \mathrm{Pb}^{2+}$ with a detection limit of $8.5 \times 10^{-6} \mathrm{M}$. The response time was $15 \mathrm{~s}$ and the lifetime 3 months. The sensor works in a $\mathrm{pH}$ range from 5-7.5 with good selectivity coefficients and was used as an indicator electrode in the potentiometric titration of the lead ion [2].

Copper has a vital importance in many biological systems and it is used for many industrial, agricultural and domestic purposes. It is toxic at high level concentrations so its determination in medicinal, environmental and industrial samples is very important. One copper-selective sensor based on meso-tetrakis-[4-(diallylmethylsilyl)phenyl]porphyrin was reported previously [3]. The sensor had a working concentration range between $4.4 \times 10^{-6}-1.0 \times 10^{-1} \mathrm{M}$ with a Nernstian slope of $29.3 \mathrm{mV} / \mathrm{decade}$ of activity in a $\mathrm{pH}$ range 2.8-7.9. The response time was about $8 \mathrm{~s}$ with a 4 months lifetime. The utility of the sensor was demonstrated by determining copper in vegetable foliage and swimming pool water samples. Other porphyrin-based sensors for $\mathrm{Ni}^{2+}$ and $\mathrm{Zn}^{2+}$ determination have also been reported [4-10].

In connection with our previous concerns about the use of porphyrins in the construction of ion selective electrodes $[11,12]$, in the present paper, two functionalized porphyrins: 5,10,15,20-tetrakis(3,4-dimethoxyphenyl) porphyrin (A) and 5,10,15,20-tetrakis(3-hydroxyphenyl)porphyrin (B) synthesized and characterized by us as reported earlier [13] were tested as ionophores for cationselective electrodes in polymeric matrix. Different membrane compositions were made by varying the amount of ionophore, additive and by using three different plasticizers: (bis(2-ethylhexyl)sebacate(DOS), dioctylphtalate (DOP) and o-nitrophenyl octyl ether (NPOE). The best results were obtained for the membranes in the ratio I:PVC:KTClPB:Plasticizer 10:165:5:330. The sensitivity, selectivity, $\mathrm{pH}$ influence and effect of the plasticizer on the behavior of the sensors were studied and the obtained results are presented below.

The sensors were used for a period of four months and their utility has been tested in synthetic and real samples. 


\section{Results and Discussion}

\subsection{Response characteristics of the electrodes}

The potentiometric answer of each ISE depends not only on the nature of the ionophore used (in our case porphyrins A and $\mathbf{B}$ shown in Figure 1), but also significantly on the nature and amount of plasticizers and additives used.

Figure 1. The structures of free base porphyrins 5,10,15,20-tetrakis(3,4-dimetoxyphenyl) porphyrin (A) and 5,10,15,20-tetrakis (3-hydroxyphenyl) porphyrin (B) used as ionophores.

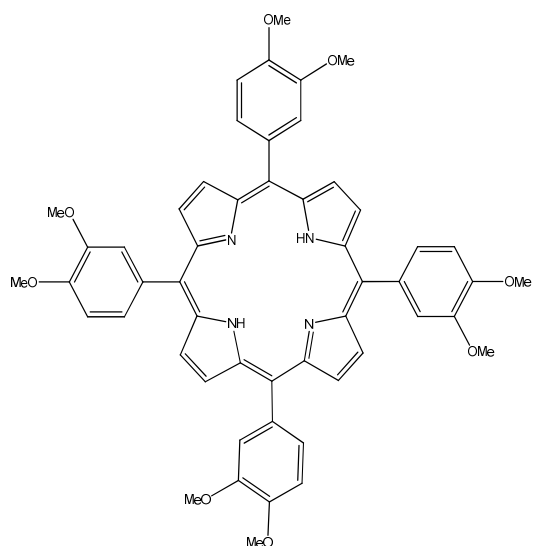

(A)

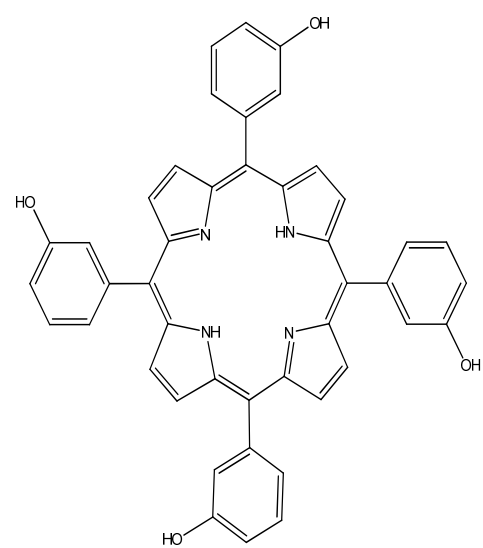

(B)

Because of these, the influence of membrane compositions having different amounts of ionophore, additive and plasticizers like (bis(2-ethylhexyl)sebacate(DOS), dioctylphtalate (DOP) and o-nitrophenyl octyl ether (NPOE) on the potentiometric response was investigated. The obtained sensors were tested in solutions from $1 \times 10^{-6}-1 \times 10^{-1} \mathrm{M}$ of the following cations: $\mathrm{Ag}^{+}, \mathrm{K}^{+}, \mathrm{Na}^{+}, \mathrm{Ni}^{2+}, \mathrm{Cu}^{2+}, \mathrm{Cd}^{2+}$, $\mathrm{Zn}^{2+}, \mathrm{Mg}^{2+}$ and $\mathrm{Pb}^{2+}$. Potassium tetrakis(4-chlorophenyl)borate (KTClPB) was used as additive to all prepared membranes.

It was found that the potentiometric answer toward silver of all the obtained sensors corresponds to the cation lipophilicity sequence (Hofmeister series of cations) [14]:

$$
\mathrm{Ag}^{+}>\mathrm{K}^{+}>\mathrm{NH}_{4}^{+}>\mathrm{Na}^{+}>\mathrm{Li}^{+}>\mathrm{Ca}^{2+}>\mathrm{Pb}^{2+}>\mathrm{Cu}^{2+}
$$

and it is presented in Table 1 and Figure 2. A sensor with a blank membrane having the composition PVC:KTCIPB:Plasticizer $=165: 5: 330$ showed a working concentration range for silver from $10^{-3}$ to $10^{-1} \mathrm{M}$ with a sub-Nernstian slope of $(20-24) \mathrm{mV} /$ decade. This is the reason why the obtained results are ascribed to the porphyrins $\mathbf{A}$ and $\mathbf{B}$ used as ionophores.

The response toward silver was sub-Nernstian for the electrodes 1-3 and 6, but the increase of the ionophore and additive amount in the membrane composition conducts to electrodes having slopes closer to theoretical value and good working concentration range. The best results were obtained for sensor no. 5, based on porphyrin $\mathbf{A}$ and having NPOE as a plasticizer in the membrane, which has a working concentration range of $1 \times 10^{-5}-1 \times 10^{-1} \mathrm{M}$ and a slope of $57.9 \mathrm{mV} /$ decade of activity and for 
sensor no. 8, based on porphyrin $\mathbf{B}$ and plasticized with DOS, with a working concentration range from $8 \times 10^{-6}-1 \times 10^{-1} \mathrm{M}$ and a slope of $64.5 \mathrm{mV} /$ decade of activity.

Table 1. Composition of PVC membranes of (A) and (B) and response characteristics of $\mathrm{Ag}^{+}$selective electrodes based on them.

\begin{tabular}{|c|c|c|c|c|c|c|c|c|c|}
\hline \multirow[b]{2}{*}{ Sensor } & \multirow{2}{*}{$\begin{array}{c}\text { Ionophore } \\
\text { (I) }\end{array}$} & \multicolumn{6}{|c|}{ Composition of membranes (w/w) } & \multirow{2}{*}{$\begin{array}{c}\text { Working } \\
\text { conc. range } \\
\text { (M) }\end{array}$} & \multirow{2}{*}{$\begin{array}{c}\text { Slope } \\
\text { (mV/decade) }\end{array}$} \\
\hline & & $\mathbf{I}$ & PVC & Add & DOS & DOP & NPOE & & \\
\hline 1 & \multirow[t]{6}{*}{ A } & 5 & 165 & 2 & - & 330 & - & $5 \times 10^{-5}-1 \times 10^{-1}$ & 31.5 \\
\hline 2 & & 5 & 165 & 2 & 330 & - & - & $1 \times 10^{-5}-1 \times 10^{-1}$ & 26.9 \\
\hline 3 & & 5 & 165 & 2 & - & - & 330 & $1 \times 10^{-5}-5 \times 10^{-2}$ & 32.2 \\
\hline 4 & & 10 & 165 & 5 & 330 & - & - & $1 \times 10^{-5}-1 \times 10^{-1}$ & 49.7 \\
\hline 5 & & 10 & 165 & 5 & - & - & 330 & $1 \times 10^{-5}-1 \times 10^{-1}$ & 57.9 \\
\hline 6 & & 5 & 150 & 2 & 200 & - & - & $5 \times 10^{-4}-1 \times 10^{-1}$ & 35.4 \\
\hline 7 & \multirow[t]{3}{*}{ B } & 10 & 165 & 5 & - & 330 & - & $3 \times 10^{-5}-1 \times 10^{-1}$ & 61.9 \\
\hline 8 & & 10 & 165 & 5 & 330 & - & - & $8 \times 10^{-6}-1 \times 10^{-1}$ & 64.5 \\
\hline 9 & & 10 & 165 & 5 & - & - & 330 & $1 \times 10^{-5}-1 \times 10^{-1}$ & 55.8 \\
\hline
\end{tabular}

Figure 2. Potentiometric response of the sensors 1-6 based on ionophore $\mathbf{A}$ and 7-9 based on ionophore $\mathbf{B}$ toward $\mathrm{Ag}^{+}$.
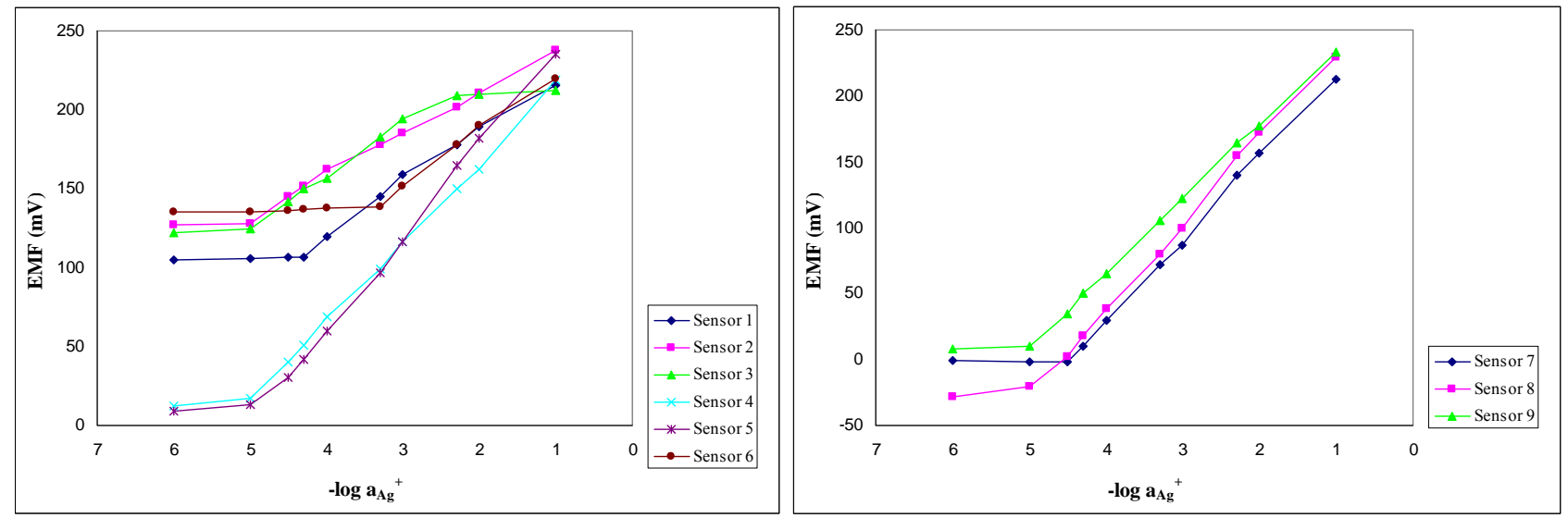

\subsection{Potentiometric selectivity}

Selectivity is perhaps the most important characteristic of any sensor which defines the extent to which it may be employed in the determination of a particular ion in the presence of the other interfering ions. The selectivity coefficients, $\log \mathrm{K}_{\mathrm{Ag}, \mathrm{X}}^{\mathrm{pot}}$, were calculated by separate solution method (SSM) [15] and are comparatively presented in figure 3.

Analyzing the values of the selectivity coefficients it results that all the obtained sensors are silverselective, the best results being obtained again for sensors no. 5 and 8 which have very good selectivity for silver over all the other tested cations. 
Figure 3. Selectivity coefficients of the sensors 1-6 based on ionophore A and 7-9 based on ionophore B calculated by separate solution method (SSM).
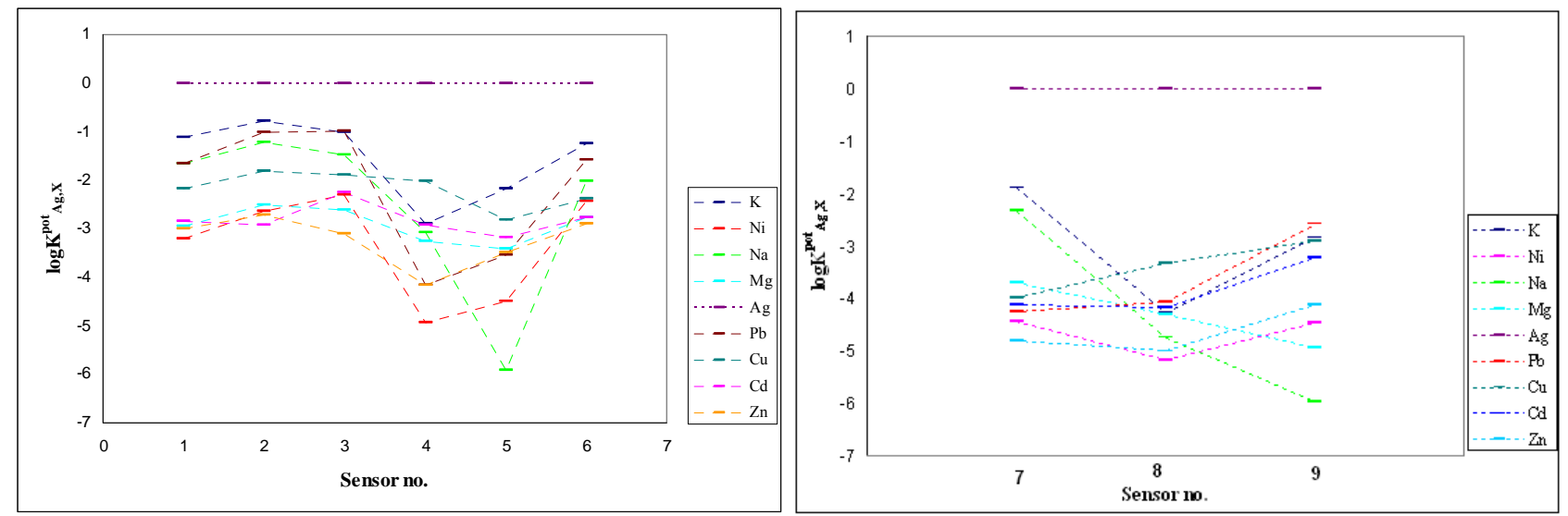

From Figure 3 it can be seen that sensors no. 4 and 9, with the exception of silver, do not respect the Hofmeister sequence for cations. For sensor no. 4 the sequence is:

$$
\mathrm{Ag}^{+}>\mathrm{Cu}^{2+}>\mathrm{K}^{+}>\mathrm{Cd}^{2+}>\mathrm{Na}^{+}>\mathrm{Mg}^{2+}>\mathrm{Pb}^{2+}>\mathrm{Zn}^{2+}>\mathrm{Ni}^{2+}
$$

So, in the absence of silver, the sensor no. 4 based on porphyrin A plasticized with DOS could be used as a copper-selective electrode, the answer to copper being presented in Figure 4.

Figure 4. Potentiometric response of the sensor no. 4 based on ionophore $\mathbf{A}$ toward $\mathrm{Cu}^{2+}$.

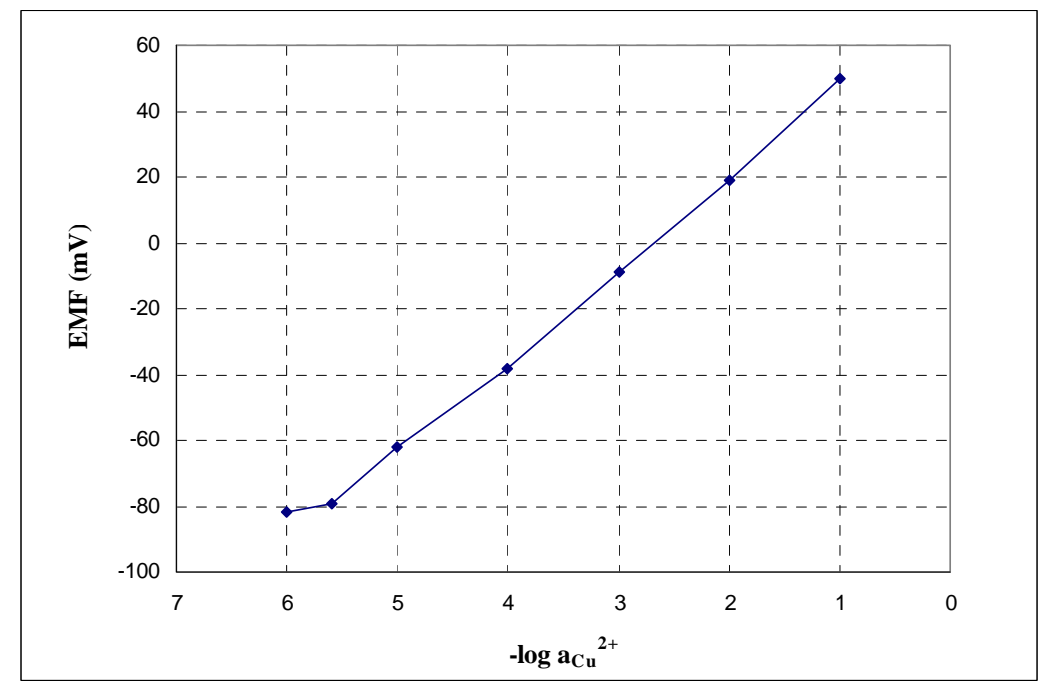

The sensor has a working concentration range of $2.5 \times 10^{-6} \mathrm{M}-1 \times 10^{-1} \mathrm{M}$, a slope of $27.8 \mathrm{mV} / \mathrm{decade}$ copper, a detection limit of $2 \times 10^{-6} \mathrm{M}$ and a moderate selectivity over the other tested cations (with the exception of silver which interferes totally).

Sensor no. 9, based on porphyrin B plasticized with NPOE, could be used, in the absence of silver, as a lead-selective sensor, having the sequence of cations:

$$
\mathrm{Ag}^{+}>\mathrm{Pb}^{2+}>\mathrm{K}^{+}>\mathrm{Cu}^{2+}>\mathrm{Cd}^{2+}>\mathrm{Zn}^{2+}>\mathrm{Ni}^{2+}>\mathrm{Mg}^{2+}>\mathrm{Na}^{+}
$$

The sensor could be used in the range $5 \times 10^{-6}-1 \times 10^{-1} \mathrm{M}$ with a slope of $25.8 \mathrm{mV} /$ decade of activity lead. The potentiometric answer of the sensor is presented in Figure 5. 
Figure 5. Potentiometric response of the sensor no. 9 based on ionophore $\mathbf{B}$ toward $\mathrm{Pb}^{2+}$.

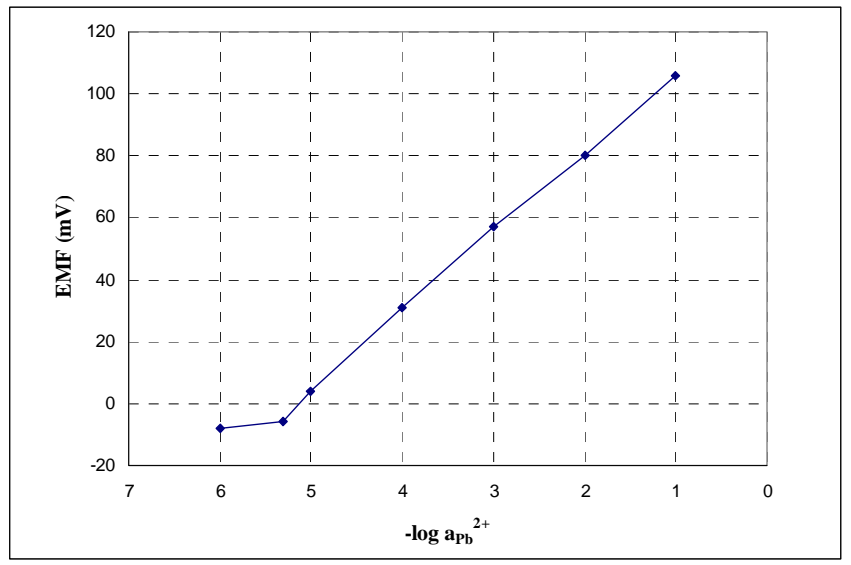

The reproductibility of the sensors was determined by a repeated monitoring of potentials (15 measurements) on the same portion of sample. The standard deviation obtained for sensors no. 8,4 and 9 was $\pm 1.8 \mathrm{mV}, \pm 1.5 \mathrm{mV}$ respectively $\pm 1.2 \mathrm{mV}$.

\subsection{Effect of the $\mathrm{pH}$}

The influence of the $\mathrm{pH}$ of the test solutions on the potential response of the electrodes was studied in the $\mathrm{pH}$ range $2.0-10.0$ in the $0.01 \mathrm{M} \mathrm{NaCl}$ solution (adjusted with $\mathrm{HNO}_{3}$ and $\mathrm{NaOH}$ ). The results are given in the figure 6 .

All membranes plasticized with DOS and NPOE displays same $\mathrm{pH}$ sensitivity in acidic solutions probably because of the partial protonation of porphyrins. The potentiometric response of the sensors no. 8 and 9 based on tetra-(3-hydroxyphenyl)porphyrin plasticized with DOS and NPOE are independent of $\mathrm{pH}$ in the $\mathrm{pH}$ range 5-10 and 5-9 respectively. The response of the membranes with ionophore $\mathbf{A}$, tetra-(3,4-dimethoxyphenyl) porphyrin and DOS are independent of $\mathrm{pH}$ in the range 510. The sensor no. 5, based on the same porphyrin with NPOE, displays a $\mathrm{pH}$ response with a slope of about $30 \mathrm{mV} /$ decade and it was not used for analytical applications.

Figure 6. Effect of the $\mathrm{pH}$ of the test solution on the potential response of the sensors with best potentiometric answers.

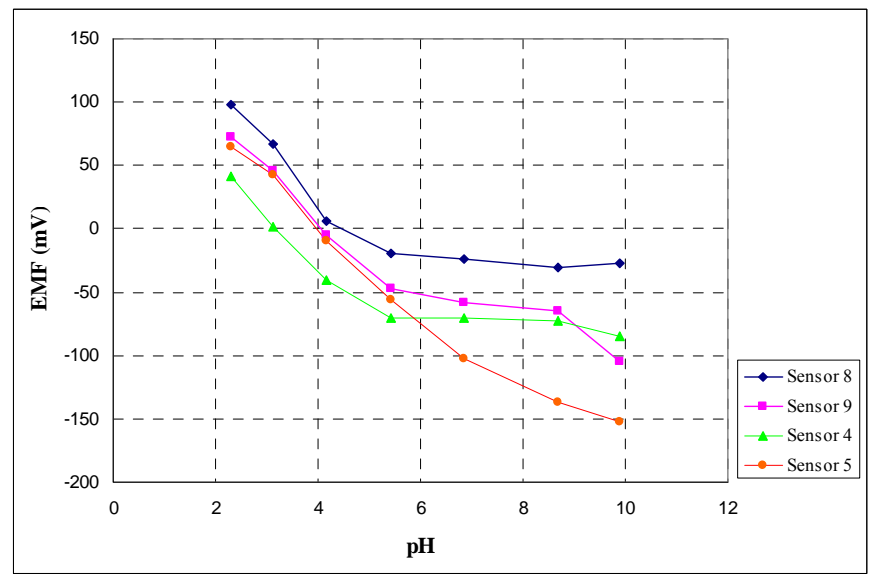




\subsection{Analytical applications}

Silver-selective sensor

The silver-selective sensor (sensor no. 8) was used to determine chloride from meat products by potentiometric titration. Volhard titration adopted as reference method was carried to compare the results obtained for chloride potentiometric determination. For each type of meat product the methods were applied on four samples. The obtained results are presented in Table 2:

Table 2. Chloride $(\mathrm{g} / \mathrm{kg})$ in different meat products determined by potentiometric titration (using sensor no. 8) and Volhard titration.

\begin{tabular}{|c|c|c|}
\hline Meat product & Potentiometric titration & Volhard titration \\
\hline Pate & $12,3 \pm 0,1$ & $12,4 \pm 0,1$ \\
Parizer & $13,2 \pm 0,2$ & $13,1 \pm 0,3$ \\
Salami & $13,5 \pm 0,1$ & $13,6 \pm 0,2$ \\
Sausage & $15,9 \pm 0,1$ & $16,0 \pm 0,2$ \\
\hline
\end{tabular}

\section{Lead-selective sensor}

The practical applicability of the $\mathrm{Pb}^{2+}$-selective sensor (sensor no. 9) was made to determine lead from synthetic and real samples. For the potentiometric determination of lead measurements were carried out by standard addition method. The results were compared with those obtained by atomic absorption spectrometry (AAS) and are presented in Table 3.

The results obtained by potentiometry were in good agreement with those obtained by AAS. The recovery tests for synthetic samples, by potentiometry with the sensor, are situated in the range $99.1-101.6 \%$.

Table 3. Determination of lead in synthetic and real samples by potentiometry (using sensor no. 9) and by AAS.

\begin{tabular}{|c|c|c|c|}
\hline Sample & $\begin{array}{c}\text { Potentiometric } \\
\mathbf{\mu g} / \mathbf{m l} \pm \text { SD (n = 4) }\end{array}$ & $\begin{array}{c}\text { AAS } \\
\mathbf{\mu g} / \mathbf{m l} \pm \text { SD (n= 4) }\end{array}$ & $\begin{array}{c}\text { Recovery } \\
\mathbf{\%}\end{array}$ \\
\hline $1^{*}$ & $11.1 \pm 0.3$ & $10.3 \pm 0.2$ & 99.1 \\
\hline $2^{*}$ & $31.6 \pm 0.4$ & $30.9 \pm 0.3$ & 101.6 \\
\hline $3^{*}$ & $41.7 \pm 0.3$ & $41.0 \pm 0.2$ & 100.6 \\
\hline wastewater & $30.1 \pm 0.4$ & $29.8 \pm 0.2$ & \\
\hline \multicolumn{4}{|r}{ synthetic samples } \\
\end{tabular}

\section{Copper-selective sensor}

The copper-selective sensor (sensor no. 4) was used to determine $\mathrm{Cu}^{2+}$ from synthetic samples by direct potentiometry and by standard addition method. The obtained results are presented in Table 4 comparative to those obtained by AAS. 
Table 4. Determination of copper in synthetic samples.

\begin{tabular}{|c|c|c|}
\hline Method & ${ }^{*} \mathbf{m g} / \mathbf{m L ~} \mathbf{C u}^{2+}$ & Recovery $\%$ \\
\hline Direct potentiometry & $3.24 \pm 0.3$ & 96.1 \\
\hline Standard addition potentiometry & $3.23 \pm 0.4$ & 95.8 \\
\hline AAS & $3.33 \pm 0.2$ & 98.8 \\
\hline
\end{tabular}

*Sample content: $3.37 \mathrm{mg} / \mathrm{ml} \mathrm{Cu}^{2+}$; Average of four measurements

\section{Conclusions}

Two functionalized porphyrins were tested as ionophores in polymeric membrane cation-selective electrodes. The best results as silver-selective electrodes were obtained for the membrane based on tetra-(3-hydroxyphenyl) porphyrin (B) plasticized with DOS which has a working concentration range from $8 \times 10^{-6}-1 \times 10^{-1} \mathrm{M}$, a slope of $(64.5 \pm 1.8) \mathrm{mV} /$ decade of activity and very good values of the selectivity coefficients. The detection limit of the sensor is $7.0 \times 10^{-6} \mathrm{M}$. The useful pH-range is $5-10$. The sensor was used for the determination of chlorides in meat by potentiometric titration.

In the absence of silver, the sensor having a membrane based on tetra-(3,4-dimetoxyphenyl) porphyrin (A) plasticized with DOS could be used in a $\mathrm{pH}$ range from 5-10 as a copper-selective electrode with a working concentration range of $2.5 \times 10^{-6} \mathrm{M}-1 \times 10^{-1} \mathrm{M}$, a slope of $(27.8 \pm 1.5)$ $\mathrm{mV} /$ decade copper, a detection limit of $2 \times 10^{-6} \mathrm{M}$ and a moderate selectivity over the other tested cations. The sensor was used for the determination of copper from synthetic samples.

The sensor based on tetra-(3-hydroxyphenyl) porphyrin with NPOE as plasticizer could be used in a $\mathrm{pH}$ range from 5-9, in the absence of silver which interferes, as a lead-selective sensor. It has a linear range from $5 \times 10^{-6}-1 \times 10^{-1} \mathrm{M}$ with a slope of $(25.8 \pm 1.0) \mathrm{mV} /$ decade of activity lead and a detection limit of $3 \times 10^{-6} \mathrm{M}$. The sensor was used for the determination of lead from real and synthetic samples.

All the sensors were used for a period of 4 months.

\section{Experimental Section}

\subsection{Reagents}

The porphyrins: tetra-(3,4-dimetoxyphenyl) porphyrin (A) and tetra-(3-hydroxyphenyl) porphyrin (B) were synthesized, purified and characterized by HPLC, TLC, UV-vis, fluorescence, MS, ${ }^{1} \mathrm{H}-\mathrm{NMR}$ and ${ }^{13} \mathrm{C}$-NMR analysis, in accordance with previously published procedures [13]. For membrane preparation, poly(vinyl)chloride (PVC) high molecular weight, bis(2-ethylhexyl)sebacate (DOS), $o$-nitrophenyl octylether (NPOE), dioctylphtalate (DOP), potassium tetrakis(4-chlorophenyl)borate (KTClPB) and tetrahydrofuran (THF) were purchased from Fluka and Merck. All salts, acids and base were of analytical reagent grade. Double distilled water was used. The performance of each sensor was investigated by measuring its potential in the concentration range $10^{-6}-10^{-1} \mathrm{M}$ of different cationic solutions. $0.1 \mathrm{M}$ stock solutions were prepared by dissolving metal nitrates in double distilled water and standardized if necessary. All working solutions were prepared by gradual dilution of the stock solutions. 


\subsection{Electrode preparation and measurements}

A mixture $(250 \mathrm{mg})$ of PVC, plasticizer, ionophore (porphyrins) and the ionic additive, in different ratios were mixed in THF $(10 \mathrm{~mL})$ and was intensively stirred until all components were dissolved. The homogeneous liquid was poured on the conductive support $(\mathrm{Cu})$ of the sensor. After, THF was allowed to evaporate at room temperature $(48 \mathrm{~h})$; the membrane of the sensor $(0.5 \mathrm{~mm}$ thick $)$ was formed. Prior to EMF measurements, all the sensors were conditioned for $48 \mathrm{~h}$ by soaking in $0.01 \mathrm{M}$ $\mathrm{NaCl}$. The measurements were carried out at room temperature with a Mettler Toledo $\mathrm{pH} /$ ion analyzer by setting up the following cell:

\section{Conductive support $(\mathrm{Cu}) / \mathrm{PVC}$ membrane/test solution/ $\mathrm{Hg}, \mathrm{Hg}_{2} \mathrm{Cl}_{2}, \mathrm{KCl}$ (sat)}

Potentiometric selectivity coefficients were determined according to the separate solution method by using the experimental EMF values obtained for $0.01 \mathrm{M}$ of the tested cations and a theoretical slope of $59.2 \mathrm{mV} /$ decade of activity for the primary cation (silver). The detection limit of each sensor was established at the point of intersection of the extrapolated linear mid-range and final low concentration level segments of the calibration plot.

\subsection{Sample extraction for chloride determination}

Meat product (10 g), previously homogenized, was weight and transferred into a $200 \mathrm{~mL}$ volumetric flask with water $(100 \mathrm{~mL})$. The solution was stirred and heated $\left(80^{\circ} \mathrm{C}\right)$ for 30 minutes. After cooling, 2 $\mathrm{mL}$ of each Carrez reagent were added under stirring, allowed to settle (30 minutes) and then diluted to volume with deionized water. Finally, the solution was shaken and then filtered through filter paper into a $200 \mathrm{~cm}^{3}$ Erlenmeyer flask clean and dried. Extracted sample solution $(20 \mathrm{~mL})$ was used for each type of meat product in the potentiometric titration with silver nitrate $0.1 \mathrm{~N}(\mathrm{~F}=1.00)$. The same volume of extracted solution was treated with excess of silver nitrate $0.1 \mathrm{~N}$, and the residual silver nitrate was determined by titration with $0.1 \mathrm{~N}$ thiocyanate solution in the presence of nitrobenzene (Volhard method).

\section{Acknowledgements}

Authors are grateful to MATNANTECH-Program and PNCDI2 because this work has been supported by Excellency Project No. 48/2006 and National Research Project No. 11-055/2007.

\section{References}

1. Mazloum Ardakani, M.; Dehghani, H.; Jalayer, M.; Zare, H.R. Potentiometric determination of silver(I) by selective membrane electrode based on derivative of porphyrin. Anal. Sci. 2004, 20, 1667-1672.

2. Sadeghi, S.; Shamsipur, M. Lead(II)-selective membrane electrode based on tetraphenylporphyrin. Anal. Lett. 2000, 33, 17-28.

3. Gupta, V.K.; Jain, A.K.; Maheshwari, G.; Lang, H.; Ishtaiwi, Z. Copper(II)-selective potentiometric sensors based on porphyrins in PVC matrix. Sens. Actuat. B 2006, 117, 99-106. 
4. Gupta, V.K.; Kumar, A.; Mangla, R. Protoporphyrin IX dimethyl ester as active material in PVC matrix membranes for the fabrication of zinc(II) selective sensor. Sens. Actuat. B 2000, 76, 617623.

5. Gupta, V.K.; Jain, A.K.; Mangla, R.; Kumar, P. A new $\mathrm{Zn}^{2+}$-selective sensor based on 5,10,15,20tetraphenyl-21H,23H-porphine in PVC Matrix". Electroanalysis 2001, 13, 1036-1040.

6. Legin, A.; Makarychev-Mikhailov, S.; Goryacheva, O.; Kirsanov, D.; Vlasov,Y. Cross-sensitive chemical sensors based on tetraphenylporphyrin and phthalocyanine. Anal. Chim. Acta 2002, 457, 297-303.

7. Gupta, V.K.; Chauhan, D.K.; Saini, V.K.; Agarwal, S.; Antonijevic, M.M.; Lang, H. A porphyrin based potentiometric sensor for $\mathrm{Zn}^{2+}$ determination. Sensors 2003, 3, 223-235.

8. Gupta, V.; Jain, A.K.; Singh, L.P.; Khurana, U. Porphyrins as carrier in PVC based membrane potentiometric sensors for nickel(II). Anal. Chim. Acta 1997, 355, 33-41.

9. Singh, L.P.; Bhatnagar, J.M. PVC-based selective sensors for nickel(2+) ions using carboxylated and methylated porphine. Sensors 2003, 3, 393-403.

10. Gupta, V.K.; Jain, A.K.; Ishtaiwi, Z.; Lang, H.; Maheshwari, G. Ni ${ }^{2+}$ selective sensors based on meso-tetrakis-\{4-[tris-(4-allyldimethylsilyl-phenyl)-silyl]-phenyl\}porphyrin and (sal) 2 trien in poly(vinyl chloride) matrix. Talanta 2007, 73, 803-811.

11. Vlascici, D.; Făgădar-Cosma, E.; Bizerea Spiridon, O. A New Composition for Co(II)-porphyrinbased Membranes Used in Thiocyanate-selective Electrodes. Sensors 2006, 6, 892-900.

12. Vlascici, D.; Bizerea Spiridon, O.; Făgădar-Cosma, E. Thiocyanate-selective electrode based on rhodium porphyrin derivatives. J. Optoelectron. Adv. M. 2006, 8, 883-887.

13. Fagadar-Cosma, E.; Cseh, L.; Badea, V.; Fagadar-Cosma, G.; Vlascici, D. Combinatorial Synthesis and Characterization of New Asymmetric Porphyrins as Potential Photosensitizers in Photodynamic Therapy. Comb. Chem. High Throughput Screen. 2007, 10, 466-472.

14. Faridbod, F.; Ganjali, M.R.; Dinarvand, R.; Norouzi, P. Developments in the field of conducting and non-conducting polymer based potentiometric membrane sensors for ions over the past decade. Sensors 2008, 8, 2331-2412.

15. Umezawa, Y.; Buhlmann, P.; Umezawa, K.; Tohda, K. Potentiometric selectivity coefficients of ion-selective electrodes. Part I. Inorganic cations. Pure Appl. Chem. 2000, 72, 1851-2082.

(C) 2008 by the authors; licensee Molecular Diversity Preservation International, Basel, Switzerland. This article is an open-access article distributed under the terms and conditions of the Creative Commons Attribution license (http://creativecommons.org/licenses/by/3.0/). 